\title{
Study on land use changes, causes and impacts by remote sensing, GISand Delphi methods in the coastal area of Ca Mau province in 30 years
}

\author{
Hanh Hong Tran ${ }^{1}{ }^{*}$, Anh Van Tran ${ }^{1}$, Nghi Thanh Le ${ }^{1}$ \\ 1 Faculty of Geomatics và Land Administration, Hanoi University of Mining và Geology, Vietnam
}

\begin{abstract}
ARTICLE INFO
ABSTRACT

Article history:

Received 15th May 2020

Revised 19th Aug. 2020

Accepted 31stAug. 2020

Keywords:

$\mathrm{CaMau}$,

Delphi,

GIS,

Land cover/ land use changes,

Remote sensing.

The main aim of this paper is to assess the spatio-temporal changes of land cover/ land use, as well as their causes and impacts of the changes in Phu Tan district of Ca Mau province in 30 years from 1989 to 2018. Multitemporal remote sensing satellite images (Landsat) were collected, and classified using supervised method. After validation and post classification, they are mapped for analysing land use/ land cover change analysis in three decades. The accuracies of the land cover/ land use maps for three timeintervals were all more than $80 \%$. Delphi method consensus analysis of expert opinion was applied in 2 rounds of survey with the consultancy of eight experts. Overall, the results show that over the last 30 years, the areas of cultivated plants and water bodies significantly decreased. In contrast, aquaculture ponds, mangrove forest, and residential areas substantially increased. These changes are driven by polical, demographic, socioeconomic and environmental factors. The major impacts include water quality, bussiness and service, and natural ecosystem. The results of this study will contribute to providing a panoramic view of the design of economic, social and environmental policies to ensure sustainable development at the district level.
\end{abstract}

Copyright @ 2020 Hanoi University of Mining and Geology. All rights reserved.

*Corresponding author

E-mail: hanhtranvub@gmail.com

DOI: 10.46326/JMES.2020.61(4).04 


\title{
Nghiên cứu sự thay đổi sử dụng đất, nguyên nhân và tác động bằng phương pháp viễn thám, GIS và Delphi tại khu vực ven biển tỉnh Cà Mau trong 30 năm
}

\author{
Trần Hồng Hạnh ${ }^{1, *}$, Trần Vân Anh ${ }^{1}$, Lê Thanh Nghị ${ }^{1}$ \\ ${ }^{1}$ Khoa Trắc địa, Bản đồ và Quản lý đất đai, Trường Đại học Mỏ - Địa chất, Việt Nam
}

THÔNGTINBÀI BÁO TÓMTẮT

Quá trình:

Nhận bài 15/05/2020

Sửa xong $19 / 08 / 2020$

Chấp nhận đăng 31/ 08/ 2020

Tù̀ khóa:

Cà Mau,

Delphi,

GIS,

Thực phủ/thay đổi sử

dụng đất,

Viễn thám.
Mục đích chính của bài báo này là để đánh giá sự thay đổi theo thò̀i gian và không gian của thực phủ/sử dụng đất, cũng như tìm hiểu nguyên nhân và tác động của sự thay đổi này ở khu vực huyện Phú Tân của tỉnh Cà Mau trong gần 30 năm tù năm 1989 đến năm 2018. Anh viễn thám đa thòi gian (Landsat) đã được thu thập và phân loại sử dụng phương pháp có giám định. Sau khi đánh giá độ chính xác và xử lý sau phân loại, các bản đồ được thành lập để phát hiện sự thay đổi thực phủ/sư dụng đất trong ba thập kỷ. Độ chính xác của các bản đồ đều đạt độ chính xác hơn $80 \%$. Phương pháp Delphi phân tích sự đồng thuận ý kiến của các chuyên gia được thực hiện trong 2 vòng với $\dot{8}$ chuyên gia. Kết quả cho thấy trong 30 năm qua, diện tích cây trồng và vùng nước tự nhiên đã giảm đáng kê. Ngược lại, diện tích ao nuôi trồng thủy sản, rùng ngập mặn và khu dân cư tăng lên rất nhiều. Các chỉ số vể chính sách, nhân khẩu hoc, kinh tế xã hội và thay đổi môi trường là nhũ̃ng nguyên nhân chính của những thay đổi này. Kết quả các tác động nhiều nhất bao gồm chất lương nước, thương mai và dich vu và hệ sinh thái tự nhiên. Những kết quả tù̀ nghiên cứu này sẽ góp phần phục vụ cho thiết kế các chính sách về kinh tế, xã hội và môi trường để đảm bảo sự phát triển bền vũng ở cấp huyện.

CC 2020 Trường Đại học Mỏ - Địa chất. Tất cả các quyền được bảo đảm.

\section{Mở đầu}

\subsection{Tình hình ngoài nước}

Thay đổi thực phủ/ sử dụng đất (LUCC) là kết quả của sự tương tác giữa con người và môi

*Tác giả liên hê

E - mail: hanhtranvub@gmail.com

DOI: 10.46326/JMES.2020.61(4).04 trường (Lambin và nnk., 2003). Ở nhiều quốc gia, LUCC được đặc trưng bởi nạn phá rừng, mở rộng đất nông nghiệp và các khu vực đô thị hóa (Tian và nnk., 2014). Những thay đổi này đặc biệt quan trọng, về cường độ và tốc độ ở các khu vực Đông Nam Á, Châu Mỹ Latinh và Châu Phi, những nơi đang trải qua quá trình chuyển đổi nhân khẩu học, kinh tế và chính trị nhanh chóng. Cụ thể đối với các khu vực ven biển thấp của vùng nhiệt đới, việc mở rộng nuôi trồng thủy sản đã được ghi nhận có LUCC đáng kể trong những thập kỷ qua (Ali, 
2006). Môi trường ven biển và đồng bằng là những nơi tập trung mật độ dân số cao nhất và có nhiều các hoạt động kinh tế (Pech và Sunada, 2008). Điều này dẫn đến áp lực nhân khẩu và thay đổi trên các hệ thống này, bao gồm cả LUCC.

Đã có rất nhiều nghiên cứu quan trọng về LUCC ở vùng ven biển, vùng cửa sông và đồng bằng sử dụng dữ liệu viễn thám trên thế giới (Gitau và Bailey, 2012; Corner và nnk., 2014). Trong nhiều nghiên cứu về vùng ven biển và khu vực đồng bằng, nguyên nhân diện tích rừng giảm mạnh theo thời gian do phát triển đô thị và các hoạt động của con người (Prabaharan và nnk., 2010), trong khi bề mặt đô thị, vùng cây bụi, trang trại nuôi tôm và mặt nước (tự nhiên và nhân tạo) tăng với tốc độ cao (Dewan và nnk., 2012). Ở một số vùng, nông nghiệp đất giảm đáng kể (Sheeja và nnk., 2010).

\subsection{Tình hình trong nước}

Lớp thựcphủ/ sử dụng đất (LULC) ở đồng bằng sông Cửu Long đã thay đổi mạnh mẽ trong những năm qua do nhiều loại yếu tố về sinh học, kinh tế và xã hội. Một số nghiên cứu đã cố gắng nghiên cứu và mô tả vùng LUCC ở một số huyện khác nhau của tỉnh Cà Mau, khu vực phía nam của đồng bằng ở Việt Nam (Binh và nnk., 2005; Lam-Dao và nnk., 2011) hoặc ở đồng bằng sông Cửu Long (Sohail, 2012; Karila và nnk., 2014). Tuy nhiên, những nghiên cứu này đã được phân tích sự thay đổi trong một khoảng thời gian ngắn hoặc ở độ phân giải không gian hoặc thời gian thấp. Những nghiên cứu đã kết luận rằng diện tích rừng ngập mặn, rừng tràm và đất nông nghiệp giảm đáng kể, chúng chủ yếu chuyển đổi sang nuôi trồng thủy sản và đất nông nghiệp. Sự thay đổi diễn ra mạnh mẽ do thời kỳ chiến tranh, các chính sách, sự xâm nhập mặn, sự phát triển kinh tế - xã hội, cùng nhiều yếu tố khác.

Phương pháp Delphi nhằm đạt được sự đồng thuận giữa các ý kiến chuyên gia về việc lựa chọn các chỉ số để mô tả các nguyên nhân và tác động của LUCC. Phương pháp này đã được ứng dụng trong các nghiên cứu cho một số vùng ở Việt Nam như: xác định các chỉ số phát triển bền vững ở tỉnh Quảng Trị của Việt Nam (Hai và nnk., 2009), các dự án cơ chế phát triển sạch (Hugé và nnk. 2010), sa mạc hóa ở tỉnh Bình Thuận của Việt Nam (Gobin và nnk., 2012).

Mục đích chính của nghiên cứu này là đánh giá sự thay đổi về không gian, thời gian của các loại lớp thực phủ/ sử dụng đất, xác định các nguyên nhân và tác động tại huyện ven biển Phú Tân, tỉnh Cà Mau trong 30 năm qua. Nghiên cứu được thiết kế để giải quyết các mục tiêu sau đây: (i) Xác định và lập bản đồ các loại LULCở huyện Phú Tân trong các khoảng thời gian 1989, 2002, và 2018; (ii) Phân tích sự phân bố không gian và thời gian của LUCC và tốc độ thay đổi này xảy ra trong các khoảng thời gian này; (iii) Xác định các chỉ số có ý nghĩa về nguyên nhân và tác động về kinh tế xã hội và môi trường của LUCC trong khu vực huyện Phú Tân.

Hiện tại, chưa có nghiên cứu nào đề cập đến LUCC sử dụng phương pháp Viễn thám và GISmột cách chi tiết tại vùng thực nghiệm ở huyện Phú Tân, vùng ven biển phía tây của Cà Mau. Ngoài ra, cũng chưa có nghiên cứu nào sử dụng phương pháp Delphi cho việc tìm hiểu chuyên sâu nguyên nhân và tác động của LUCC liên quan đến các yếu tố kinh tế - xã hội và môi trường ở Phú Tân. Những kết quả từ nghiên cứu này sẽ góp phần hiểu rõ trong thời gian lâu dài về nguyên nhân và ảnh hưởng của LUCC. Đồng thời bổ sung, hỗ trợ cho công tác xây dựng các chính sách hiệu quả cải thiện chất lượng cuộc sống của người dân địa phương, phát triển quản lý tài nguyên và môi trường bền vững, giảm thiểu tác động bất lợi của LUCC và các quá trình liên quan đến biến đổi khí hậu.

\section{Khu vực thực nghiệm}

Sông Cửu Long là một đồng bằng rộng lớn và bằng phẳng được hình thành do tích tụ trầm tích ở cửa sông Mê Kông và sông Bassac. Tỉnh Cà Mau là tỉnh ven biển rộng lớn nằm ở đồng bằng sông Cửu Long của miền Nam Việt Nam có sự đa dạng các loại hình sử dụng đất thấp, dễ bị ngập do độ cao tù̀ -1 đến $3 \mathrm{~m}$ so với mực nước biển và chịu ảnh hưởng bởi cả các thủy triều cao của Biển Đông và Vịnh Thái Lan (Hong và San, 1993). Huyện Phú Tân là một huyện nông thôn ven biển của tỉnh Cà Mau, huyện có 1 thị trấn và 8 xã, giáp với Vịnh Thái Lan và các huyện lân cận là Trần Văn Thời, Cái Nước và Năm Căn (Hình 1 ). Theo niên giám thống kê năm 2017 của Cục Thống kê Cà Mau cho thấy, huyện Phú Tân có tổng dân số 109.642 người; mật độ dân số là 246 người/ km² (Cục Thống kê tỉnh Cà Mau, 2017). Huyện có mạng lưới sông rạch dày đặc với đặc điểm hai mùa mưa và mùa khô, nhiệt 


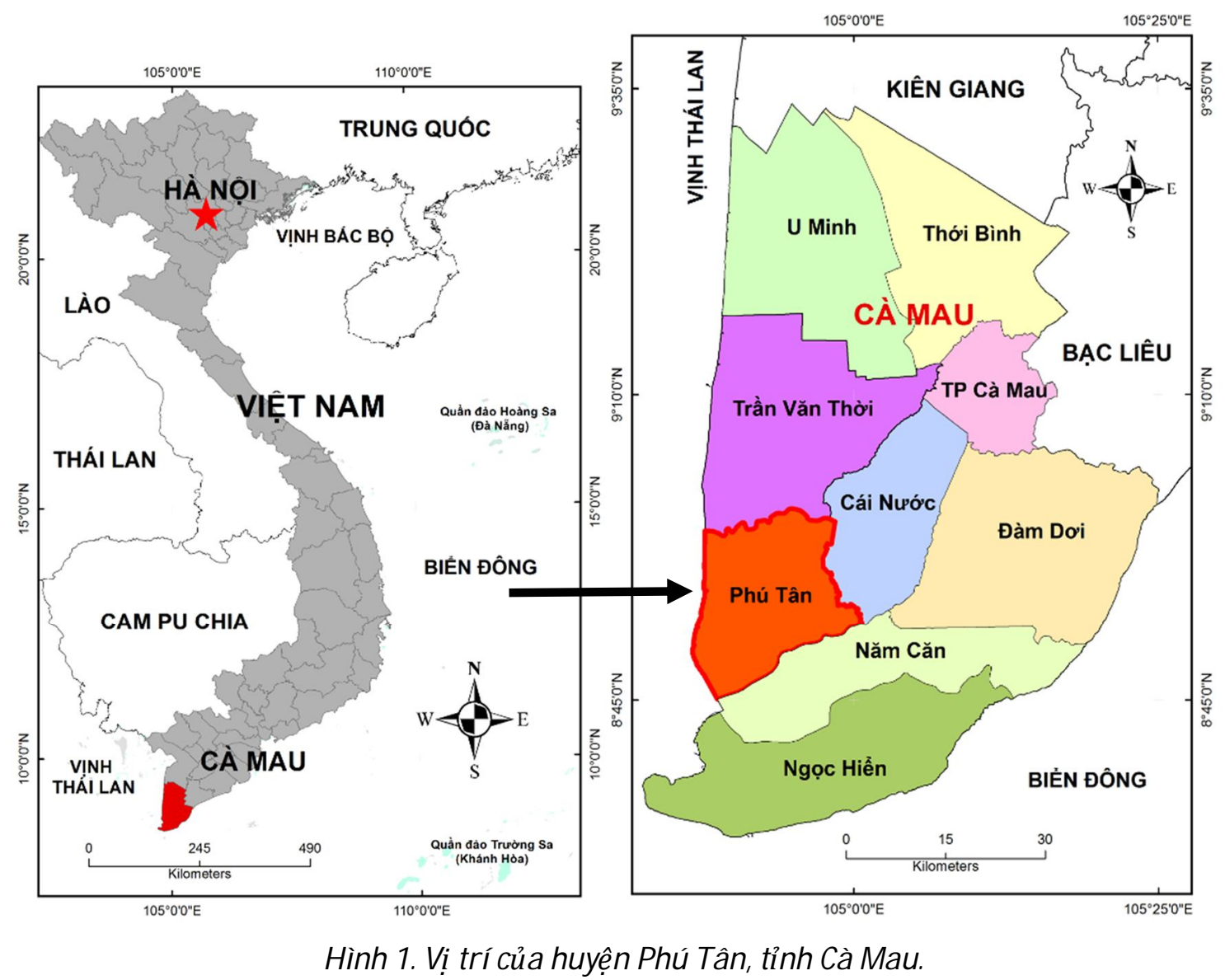

độ trung bình hàng năm là $27,5^{\circ} \mathrm{C}$ và lượng mưa trung bình hàng năm là 2442 mm.

\section{Phương pháp nghiên cứu}

\subsection{Phương pháp Viễn thám và GIS}

\subsubsection{Dũ liệu}

Sự thay đổi của các loại hình LULC đa dạng được phân tích trong các khoảng thời gian khác nhau bằng cách phân tích các dữ liệu ảnh vệ tinh quang học đa thời gian (Viễn thám). Các bản đồ LULC, cũng như các bản đồ LUCC ở các giai đoạn khác nhau sẽ được thành lập và phân tích bằng phần mềm GIS chuyên dụng.

Các phần mềm ENVI 5.0 và ARCGIS10.0 (ESRI) đã đượC sử dụng để xử lý ảnh và phân tích không gian trong nghiên cứu này. Dữ liệu được sử dụng cho nghiên cứu này bao gồm các ảnh vệ tinh Landsat TM 1989 (24/02/1989), Landsat ETM 2001 và $2002(16 / 01 / 2001$ và $17 / 03 / 2002)$, và Landsat 8 LDCM 2018 (12/03/2018) của Cục Khảo sát Địa chất Mỹ (USGS), tất cả đều có độ phân giải là 30 x 30 m. Dữ liệu tham khảo bao gồm các bản đồ địa hình năm 1988 (tỷ lệ 1:50.000), 2006 (tỷ lệ 1:50.000), 2010 (tỷ lệ 1:5.000) của Bộ Quốc phòng, năm 2002 (tỷ lệ 1:50.000) của Bộ Tài nguyên và Môi trường và các ảnh của Google Earth. Các ảnh Landsat đã được chọn dựa trên tiêu chí ít mây, theo phạm vi không gian và thời gian. Các lớp GIS có được từ các bản đồ địa hình đã cung cấp thông tin về ranh giới hành chính, đường bộ, địa hình, các vùng nước tự nhiên, thảm thực vật và cơ sở hạ tầng dân cư.

\subsubsection{Tiền xử lý ảnh}

Các ảnh vệ tinh Landsat được sử dụng trong nghiên cứu này được tải miễn phí từ Cục khảo sát địa chất Mỹ USGS. Sau đó được tiến hành hiệu chỉnh khí quyển, còn hiệu chỉnh địa hình được bỏ qua do đặc điểm địa hình thấp và bằng phẳng của tỉnh Cà Mau (Vo và nnk., 2013). Các ảnh vệ tinh đã được nắn chỉnh hình học theo UTM, múi 48N, WGS84, sử dụng phương pháp lấy mẫu láng giềng gần nhất. Mỗi cảnh ảnh đều được nắn chỉnh sử dụng 10 điểm khống chế cơ sở (GCP). Tất cả các ảnh đã được nắn với sai số RMS nhỏ hơn 0,5 pixel. 


\subsubsection{Phân loại}

Bản đồ địa hình và ảnh Google Earth đã được sử dụng cho các mẫu phân loại LULC. Đối với các khoảng thời gian trước, các bản đồ địa hình ở các năm được sử dụng để phân loại các mẫu còn chưa rõ ràng. Kinh nghiệm phân loại trực quan các ảnh cũng đã giúp chọn các mẫu phân loại ở các thời điểm trước. Số lượng và các loại LULC được xác định dựa trên số liệu thống kê sử dụng đất có sẵn của tỉnh Cà Mau và huyện Phú Tân và dựa trên phân tích phân loại không giám sát (phân loại 25 nhóm, sau đó gộp thành 5 lớp thực phủ/ sử dụng đất). Có 5 loại LULC của huyện Phú Tân đã được xác định bao gồm rừng ngập mặn, cây trồng và ăn quả, ao nuôi trồng thủy sản, dân cư và các vùng nước tự nhiên.

Bản đồ phân loại LULC được thành lập bằng phương pháp phân loại xác suất cực đại. Các mẫu phân loại dùng cho phân loại có giám sát trong nghiên cứu này đã được lựa chọn dựa trên các bản đồ tham khảo. Phân loại tách biệt mẫu tù 1,9 đến 2,0 theo phương pháp của Jeffrey Matusita được thực hiện. Bộ lọc $3 \times 3$ đã được áp dụng để giảm nhiễu trong các bản đồ LULC. Cuối cùng, các mẫu độc lập đượC sử dụng để đánh giá tính chính xác của từng phân loại (Campbell và Wynne, 2011).

\subsubsection{Phân tích biến động}

Diện tích của từng loại LULC và LUCC đã được tính toán và phân tích. Các cảnh ảnh ít mây nhất trên khu vực nghiên cứu huyện Phú Tân đượC nghiên cứu LUCC trong 2 giai đoạn ngắn (1989 2002 và 2002 - 2018) và 1 giai đoạn dài (1989 2018). Việc phát hiện LUCC bằng cách chồng xếp và xử lý sau phân loại của các bản đồ LULC trong các khoảng thời gian khác nhau ở quy mô huyện. Các bản đồ kết quả kèm theo các ma trận tương ứng hiển thị các số lượng chuyển đổi cụ thể.

\subsection{Phương pháp Delphi}

Nhiều chuyên gia có thể có kiến thức, kinh nghiệm và ý kiến khác nhau về cùng một vấn đề, phương pháp Delphi nhằm đạt được sự đồng thuận giữa các ý kiến chuyên gia về các nguyên nhân và tác động của vấn đề đó (Chu và Hwang, 2007).

Trong nghiên cứu này, sau khi có kết quả của phương pháp viễn thám, phương pháp Delphi được dùng để phân tích ý kiến chuyên gia áp dụng trong 2 vòng khảo sát với 8 chuyên gia về vấn đề LUCC. Họ bao gồm các nhà quản lý từ các sở của tỉnh (ví dụ: Tài nguyên và Môi trường, Cục Lâm nghiệp), các nhà quản lý ở cấp huyện, và các nhà nghiên cứu về Cà Mau (ví dụ như Viện Hàn lâm Khoa học và Công nghệ Việt Nam).

ở vòng 1 , bảng đánh giá bao gồm 4 nhóm lớn các chỉ số tiềm năng về nguyên nhân (các yếu tố lịch sử và chính trị (4 chỉ số), yếu tố nhân khẩu xã hội (16), yếu tố kinh tế (5), các yếu tố vật lý và môi trường (16)), tác động của LUCC (nhân khẩu - xã hội (14), tác động kinh tế (29) và tác động môi trường (12)) trong khu vực nghiên cứu được gửi tới các chuyên gia.

Mỗi chuyên gia được mời đánh giá độc lập mức độ liên quan của từng chỉ số theo thang năm cấp (mức 1 =chỉ số không liên quan, mức 2 =liên quan ít, mức $3=$ liên quan trung bình, mức $4=$ liên quan cao, mức 5 =liên quan rất cao). Kết quả của vòng đánh giá đầu tiên được tính toán các trung vị, giá trị trung bình, độ lệch tứ phân vị và phương sai của mỗi chuyên gia (Deborah, 2011). Kết quả tổng hợp này sẽ được thể hiện trong một báo cáo bằng văn bản gưii cho mỗi chuyên gia (không bao gồm kết quả đánh giá của từng người).

ở vòng 2 , mỗi chuyên gia được mời để đánh giá lại mức thang của từng chỉ số. Chuyên gia có thể quyết định giữ ý kiến của mình, hoặc họ có thể thay đổi sau khi tham khảo kết quả tổng hợp. Phương pháp Delphi dừng lại sau 2, 3 hoặc nhiều vòng sau khi tất cả các chỉ số tiềm năng được chấp nhận hoặc loại bỏ theo Hình 2 (Chu và Hwang, 2007). Trong trường hợp của nghiên cứu này, đã đạt được sự đồng thuận sau hai vòng đánh giá.

\section{Kết quả và thảo luận}

\subsection{Kết quả và thảo luận phương pháp viễn thám}

\subsubsection{Phân loại LULC và đánh giá độ chính xác}

Độ chính xác tổng thể của việc phân loại LULC ở huyện Phú Tân trong các năm 1989, 2002 và 2018 lần lượt là 88, 84 và $80 \%$. Các chỉ số Kappa lần lượt là 0,$82 ; 0,80$ và 0,74 . Các bản đồ phân loại LULC của huyện Phú Tân trong ba khoảng thời gian đã được phân tích và được thể hiện trong Hình 3. 


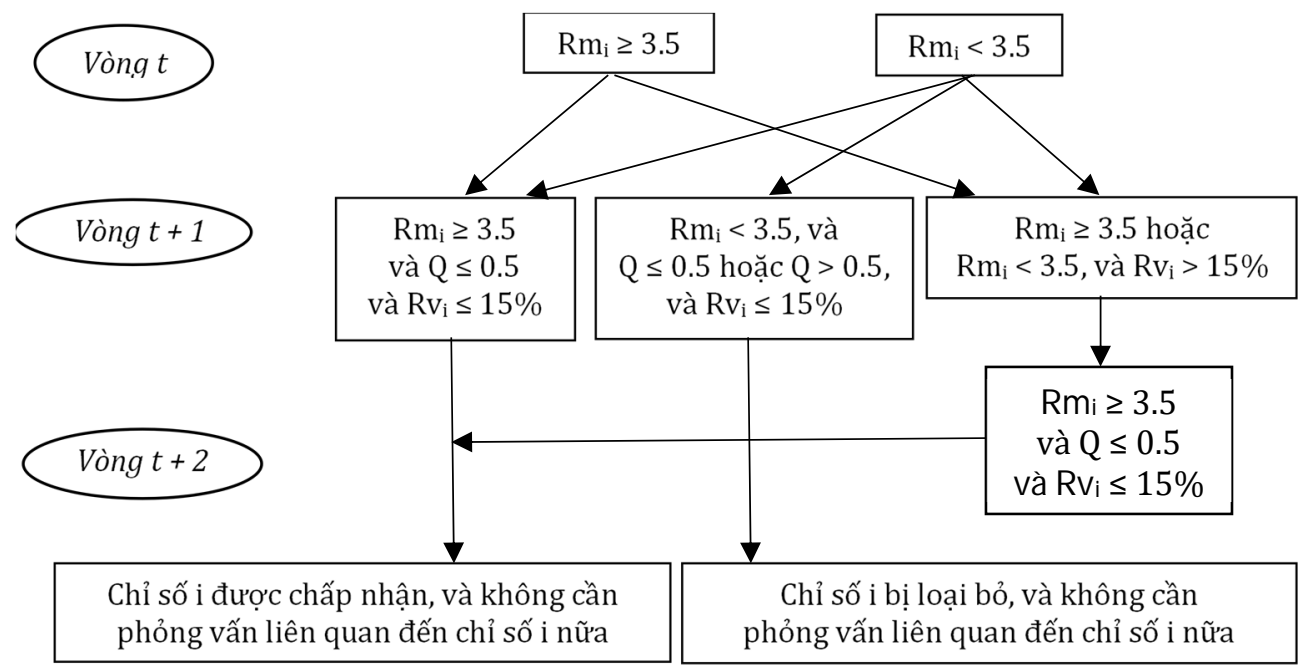

Hình 2. Quy tắc phân tích mức đánh giá của các chuyên gia bằng phương pháp Delphi (theo Chu và Hwang, 2007). (Rmi là trung bình múc đánh giá của chỉ số i; $Q$ là độ lệch tú phân vị; Phương sai $R v_{\mathrm{i}}$ là tỷ lệ các chuyên gia thay đổi đánh giá của họ cho chỉ số i giữa hai vòng).

Rừng ngập mặn nằm chủ yếu ở phía tây nam của huyện, tăng lển trong thời gian 30 năm. Trong quá khứ, rừng ngập mặn giảm đáng kể (Binh và nnk., 2005; Tran và nnk., 2015). Các yếu tố chính có thể góp phần làm mất độ che phủ rừng là chiến tranh, mở rộng trồng lúa và nuôi tôm (Lam-Dao và nnk., 2011). Tuy nhiên, các chính sách địa phương để trồng lại rừng ngập mặn đã được áp dụng trong những năm gần đây (Arnaud-Haond và nnk., 2009).

Cây trồng, hầu hết là lúa, chiếm ưu thế ở phía bắc, trung tâm và phía đông của huyện và giảm đáng kể trong năm 2018. Đất trồng trọt (lúa nước) đã được chuyển đổi sang ao nuôi trồng thủy sản, rừng ngập mặn và mở rộng các khu vực xây dựng do sự gia tăng dân số và phát triển kinh tế - xã hội (Binh và nnk., 2005) .

Trên thực tế, chỉ có ba lớp LULC trong phân loại năm 1989. Lý do là chất lượng hình ảnh của năm này không tốt cho phân loại chi tiết. Dân cư không thể được phân loại trong năm 1989 và 2002 do hình ảnh chất lượng thấp và diện tích nhỏ của dân cư tại thời điểm đó. Phổ dân cư trong những thời điểm này bị trộn lẫn với phổ cây trồng, để chúng trở thành hỗn hợp của nhà và vườn. ở những thời điểm này, rừngngập mặn và đất canh tác có thể dễ dàng được phân loại.

\subsubsection{Phân tích sự thay đổi thực phủ/ sử dụng đất}

Hình 4 minh họa sự phân bố không gian của các loại LULC thay đồi trong cáckhoảng thời gian khác nhau. Đất canh tác thay đổi trong tất cả các giai đoạn trong toàn huyện, chủ yếu là do mở rộng các ao nuôi trồng thủy sản. Việc chuyển đổi rừng ngập mặn và các vùng nước tự nhiên ở phía đông và phía tây của huyện trong giai đoạn 1989 - 2002 và 2002 - 2018.

Bảng ma trận của LUCC cụ thể ở huyện Phú Tân từ năm 1989 đến 2018 được thể hiện trong Bảng 1. Trong gần 30 năm từ 1989 đến 2015, diện tích cây trồng vẫn duy trì là 4.242 ha, nhưng từ năm 2015 đến 2018 thì 32.196 ha đất canh tác đã bị chuyển đổi sang ao nuôi trồng thủy sản (22.150 ha), rừng ngập mặn (9.758 ha), dân cư (116 ha) và nước tự nhiên (171 ha). Các khu vực rừng ngập mặn và vùng nước tự nhiên cũng đã thay đổi thành ao nuôi trồng thủy sản, với diện tích tương ứng là 1.010 và 1.120 ha.

Kết quả nghiên cứu khá tương đồng với kết quả phân tích chuyển đổi LULCtrong quá khứ (Binh và nnk., 2005; Lam-Dao và nnk., 2011; Tran và nnk., 2015) với các nghiên cứu ở các huyện khác trong cùng tỉnh. Các nghiên cứu cũng chỉ ra rằng các trang trại nuôi tôm đã tăng gấp cả chục lần hoặc hơn, cùng với đó diện tích dân cư cũng tăng đáng kể, ngược lại với sự giảm rõ rệt của rừngngập mặn và đất canh tác.

\subsection{Kết quả và thảo luận phương pháp Delphi}

Tổng hợp các chỉ số về nguyên nhân bao gồm 4 yếu tố lớn là lịch sử/ chính sách, yếu tố nhân khẩu - xã hội, kinh tế và môi trường. ở quy mô cấp huyện, nhiều chỉ số nguyên nhân chính được chọn 

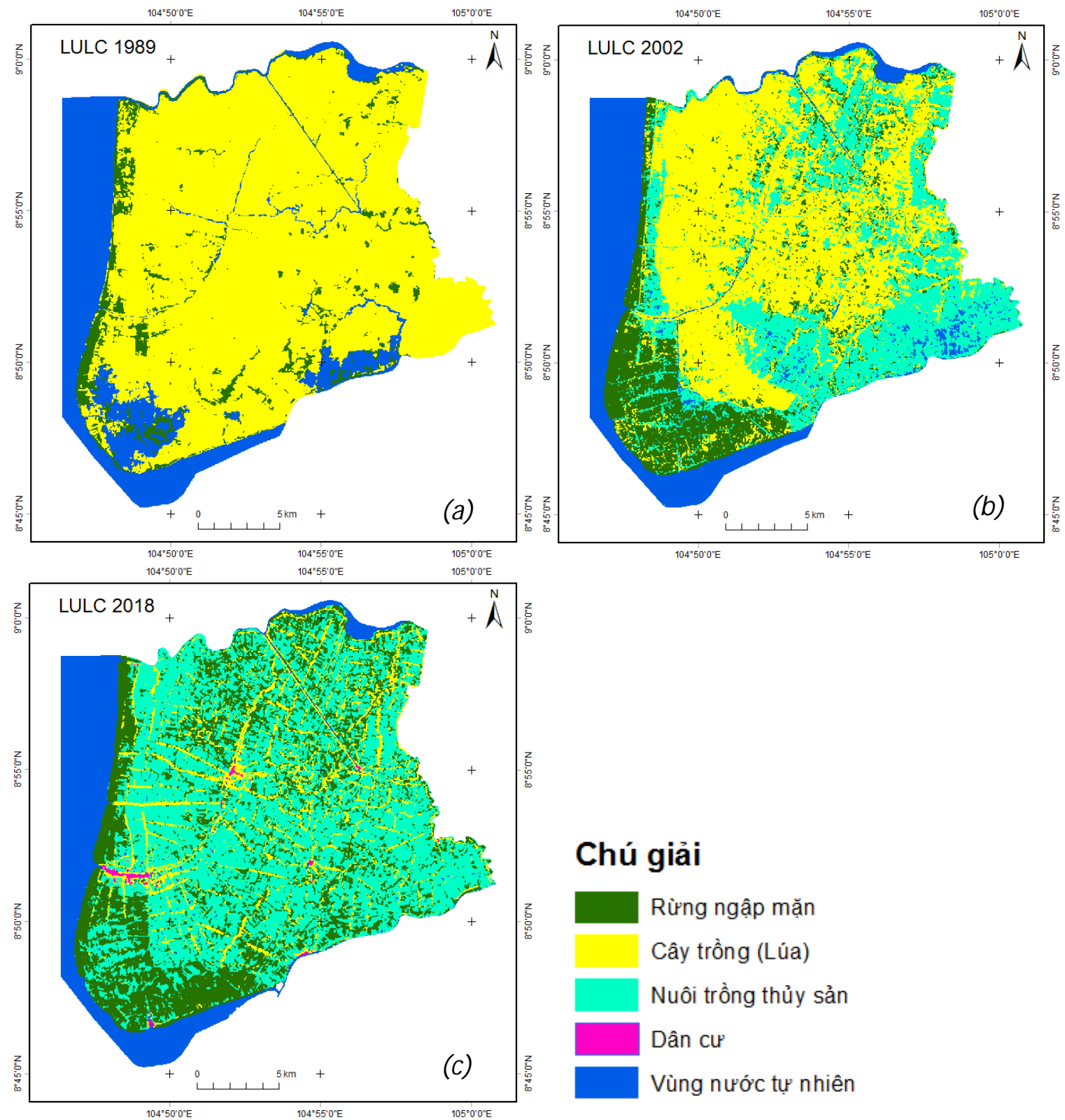

\section{Chú giải}

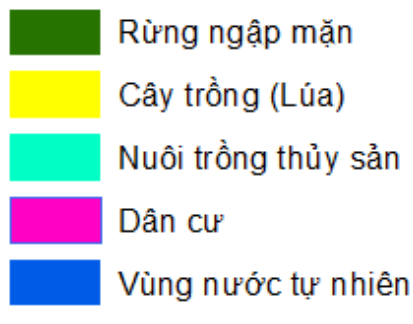

Hình 3. Các bản đồ phân loại lớp thực phủ/ sử dụng đất (LULC) huyện Phú Tân các năm 1989, 2002, và 2018. (a) bản đồ phân loại LULC năm 1989; b) bản đồ phân loại LULC năm 2002; c) bản đồ phân loại LULC năm 2018).

từ các chuyên gia, ví dụ như chính sách, mật độ dân số, thái độ/nhận thức xã hội, thu nhập, độ mặn, mạng lưới sông và kênh, địa hình. Các chỉ số về tác động chính của LUCC theo các chuyên gia như chất lượng nước, thương mại và dịch vụ, hệ sinh thái tự nhiên (Binh và nnk., 2005; Lam-Dao và nnk., 2011; Tran và nnk., 2015) với các nghiên cứu ở các huyện khác trong cùng tỉnh, cũng chỉ ra rằng các trang trại nuôi tôm đã tăng gấp 10 lần trong giai đoạn từ năm 1999 đến 2001. Ngoài chính sách Đổi mới, hai chính sách 09/ NQ-CP năm
2000 của Chính phủ và 1116/QĐ-CTUB năm 2001 của tỉnh Cà Mau có tác động lớn đến những thay đổi sử dụng đất ở Cà Mau. Những lý do chính của việc chuyển đổi này bao gồm các chính sách được đề cập ở trên, vấn đề xâm nhập mặn và yếu tố kinh tế (thu nhập). Xâm nhập mặn liên quan trực tiếp đến việc mở rộng nuôi trồng thủy sản, cho thấy sự phát triển của ngành tôm có thể ảnh hưởng đến môi trường và gây ô nhiễm (Cao và nnk., 2007). Biến đổi khí hậu và môi trường (nước biển dâng, bão lũ, ngập lụt trong mùa mưa, xâm nhập mặn 

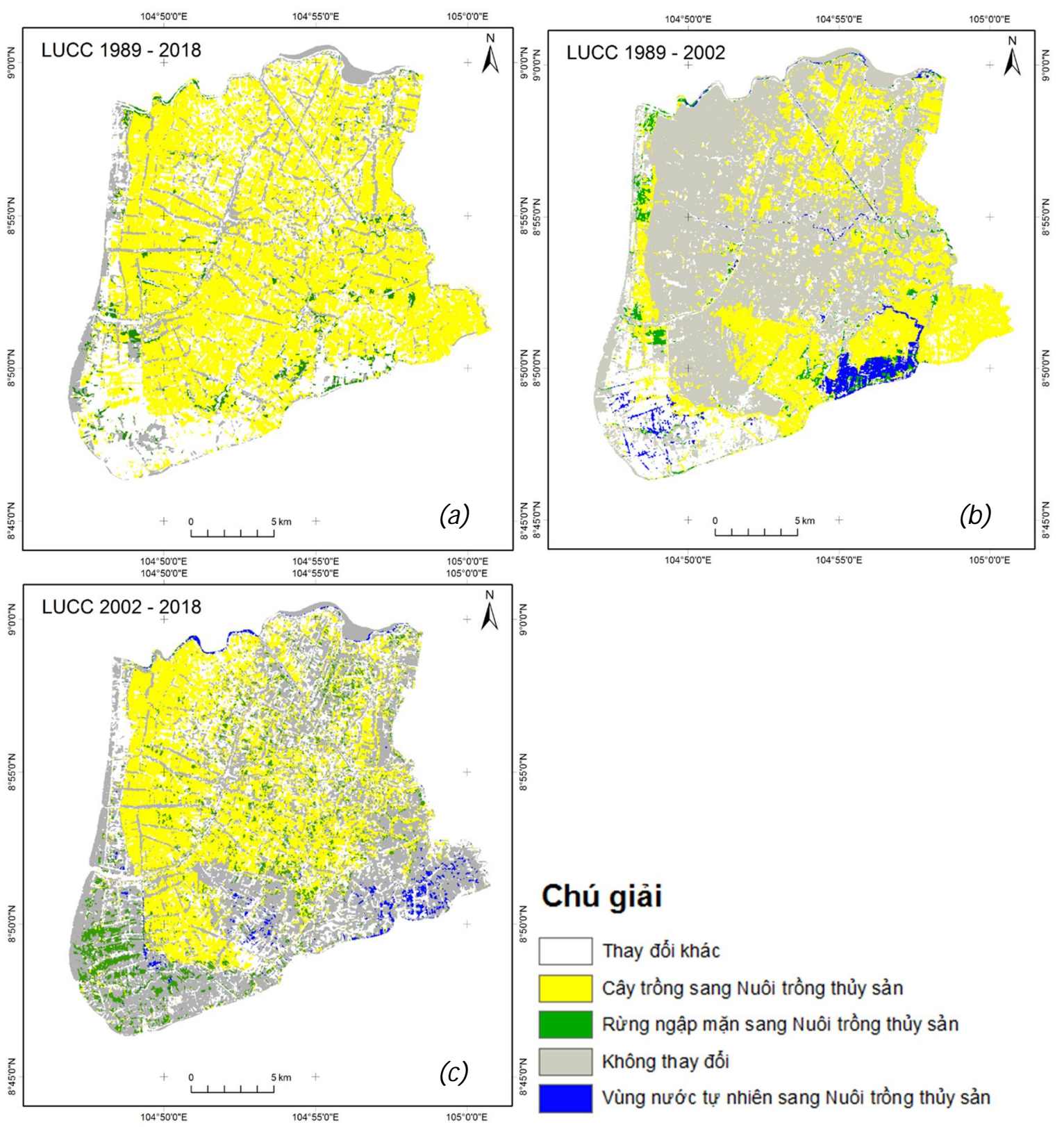

\section{Chú giải}

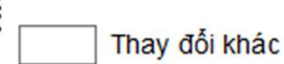

Cây trồng sang Nuôi trồng thủy sản

Rừng ngập mặn sang Nuôi trồng thủy sản

Không thay đỗi

Vùng nước tự nhiên sang Nuôi trồng thủy sản

Hình 4. Phân bố không gian thay đổi thực phủ/ sử dụng đất (LUCC) huyện Phú Tân tù̀ năm 1989 đến năm 2018. (Hình a là bản đồ LUCC năm 1989; Hình b là bản đồ LUCC năm 2002; Hình c là bản đồ LUCC năm 2018).

vào mùa khô,...), sự phát triển kinh tế và gia tăng dân số nhanh chóng được cho là đã góp phần vào sự phát triển nhanh chóng LUCCở đồng bằng sông Cửu Long nói chung và tỉnh Cà Mau nói riêng.

\section{Kết luận}

Tóm lại, trong 30 năm từ 1989 đến 2018, LULC huyện Phú Tân cho thấy những thay đổi đáng kể. Trong khi diện tích cây trồng và các vùng nước tự nhiên giảm đáng kể thì ao nuôi trồng thủy sản, rừng ngập mặn và khu dân cư đã tăng lên rất nhiều. Các nhóm yếu tố chính bao gồm lịch sử, nhân khẩu - xã hội, kinh tế và môi trường với các chỉ số chi tiết, là những nguyên nhân chính dẫn đến sự LUCC ở khu vực này. Bên cạnh đó, LUCC cũng dẫn đến các tác động khác nhau, nhưng nhiều nhất là tác động đến chất lượng nước, thương mại và dịch vụ và hệ sinh thái tự nhiên. 
Bảng 1. Sự chuyển đổi của các lóp phủ/ sử dụng đất huyện Phú Tân tù năm 1989 đến năm 2018 (ha).

\begin{tabular}{|c|c|c|c|c|c|c|c|c|}
\hline $\begin{array}{l}\text { Thứ } \\
\text { tự }\end{array}$ & \multicolumn{2}{|c|}{ Giai đoạn 1989-2002 } & $\mathbf{R u}$ & $\mathrm{Ca}$ & Ao & Da & $\mathrm{Nu}$ & $\begin{array}{l}\text { Tổng } \\
\text { (1989) }\end{array}$ \\
\hline \multirow{5}{*}{1} & \multirow{4}{*}{1989} & Rừng ngập mặn (Ru) & 1292 & 1036 & 851 & 0 & 62 & 3241 \\
\hline & & Cây trồng (Ca) & 4578 & 19921 & 11439 & 2 & 586 & 36525 \\
\hline & & Nước tự nhiên $(\mathrm{Nu})$ & 1205 & 270 & 1021 & 0 & 549 & 3045 \\
\hline & & Tổng (1989) & 7075 & 21227 & 13311 & 2 & 1197 & 42811 \\
\hline & \multicolumn{2}{|c|}{ Giai đoạn 2002-2018 } & $\mathbf{R u}$ & $\mathrm{Ca}$ & Ao & Da & $\mathrm{Nu}$ & $\begin{array}{l}\text { Tổng } \\
(2018)\end{array}$ \\
\hline \multirow{7}{*}{2} & \multirow{6}{*}{2002} & Rừng ngập mặn (Ru) & 4170 & 434 & 2438 & 9 & 23 & 7073 \\
\hline & & Cây trồng $(\mathrm{Ca})$ & 5187 & 3293 & 12554 & 87 & 102 & 21222 \\
\hline & & Ao NT Thủy sản (Ao) & 3324 & 1068 & 8774 & 48 & 90 & 13304 \\
\hline & & Dân cư (Da) & 1 & 0 & 1 & 0 & 0 & 2 \\
\hline & & Nước tự nhiên (Nu) & 171 & 83 & 554 & 15 & 374 & 1197 \\
\hline & & Tổng (2002) & 12852 & 4877 & 24321 & 160 & 589 & 42799 \\
\hline & \multicolumn{2}{|c|}{ Giai đoạn 1989-2018 } & $\mathbf{R u}$ & $\mathrm{Ca}$ & Ao & Da & $\mathrm{Nu}$ & $\begin{array}{l}\text { Tổng } \\
(2018)\end{array}$ \\
\hline \multirow{4}{*}{3} & \multirow{4}{*}{1989} & Rừng ngập mặn (Ru) & 1647 & 439 & 1010 & 26 & 26 & 3148 \\
\hline & & Cây trồng $(\mathrm{Ca})$ & 9758 & 4242 & 22150 & 116 & 171 & 36438 \\
\hline & & Nước tự nhiên $(\mathrm{Nu})$ & 1326 & 190 & 1120 & 17 & 385 & 3039 \\
\hline & & Tổng (1989) & 12731 & 4872 & 24280 & 158 & 582 & 42625 \\
\hline
\end{tabular}

Hiểu được LUCC, nguyên nhân và tác động của sự thay đổi này sẽ đóng góp kiến thức để hỗ trợ các nhà hoạch định chính sách xây dựng các chính sách hữu ích cho quy hoạch sử dụng đất trong tương lai và các chính sách kinh tế, xã hội và môi trường để đảm bảo sự phát triển bền vững của huyện nông thôn này.

\section{Lời cảm ơn}

Nhóm tác giả xin chân thành cảm ơn Trường Đại học Mỏ Địa chất đã tài trợ kinh phí để thực hiện đề tài (T19-18).

\section{Tài liệu tham khảo}

Ali,A.M. S., (2006). Rice to shrimp: Land use/ land cover changes và soil degradation in Southwestern Bangladesh. Land Use Policy 23(4), 421-435.

Arnaud-Haond, S., Duarte, C.M., Teixeira, S., Massa, S.I., Terrados, J., Tri, N.H., Hong, P.N., Serrão, E.A., (2009). Genetic recolonization of mangrove: genetic diversity still increasing in the Mekong Delta 30 years after Agent Orange. Marine Ecology Progres Series, 129-135.
Binh, T.N.K.D., Vromant, N., Hung, Nguyen Thanh, Hens, L., Boon, E.K., (2005). Land cover changed between 1968 và 2003 in Cai Nuoc, Ca Mau penisula, Vietnam. Environ. Dev. Sustain. 7, 519-536.

Campbell, J.B., Wynne, R.H., (2011). Introduction to Remote Sensing. 5th ed., The Guiford Press, New York, 662 pages.

Cao, L., Wang, W., Yang, Y., Yang, C., Yuan, Z, Xiong, S., Diana, J., (2007). Environmental impact of aquaculture và countermeasures to aquaculture pollution in China. Environmental Science và Pollution Research 14, 452-462.

Chu, H. C., Hwang, J. C., (2007). A Delphi-based approach to developing expert systems with the cooperation of multiple experts. Experts System with Application 34(4), 2826-2840.

Corner, R.J.; Ongee, E.T.; Dewan, A.M., (2014). Spatiotemporal patterns of population distribution. In Dhaka Megacity; Springer Netherlvàs: Dordrecht, The Netherlvàs; pp. 45-60. 
Deborah, J.R, (2011). Statistics dummies. Wiley Publishing, Inc., New York, 384 pages.

Dewan, A.M.; Yamaguchi, Y; Rahman, M.Z., (2012). Dynamics of land use/ cover changes và the analysis of landscape fragmentation in Dhaka Metropolitan, Bangladesh. GeoJournal 77, 315-330.

Gitau, M.; Bailey, N., (2012). Multi-layer assessment of land use và related changes for decision support in a coastal zone watershed. Lvà 1,5-31.

Gobin, A., Hai Le Trinh, Linh, P. H., Hens, L., Ozer, P., Hien, Le Thi Thu, Binh, N. T., Vinh, Pham Quang, (2012). Impact of global climate change và desertification on the environment và society in the Southern centre of Vietnam (Case study in the Binh Thuan Province) - Report of the bilateral Belgian - Vietnamese project.

Hai Le Trinh, Hai Pham Hoang, Nguyen Truong Khoa, Hens, L., (2009). Indicators for sustainable development in the Quang Tri Province, Vietnam. Journal of Human Ecology 27(3), 217-227.

Hugé, J., Trinh Hai Le, Hai Pham Hoang, Kuilman, J., Hens, L., (2010). Sustainability indicators for clean development mechanism projects in Vietnam. Environment, Development và Sustainability 12, 561-571.

Hong, P.N., San, H.T., (1993). Mangroves in Vietnam; IUCN (The International Union for Conservation of Nature và Natural Resources): Bangkok, Thailand.

Karila, K., Nevalainen, O., Krooks, A., Karjalainen, M., Kaasalainen, S., (2014). Monitoring changes in rice cultivated area from SAR và optical satellite images in Ben Tre và Tra Vinh provinces in Mekong delta, Vietnam. Remote Sens. 6, 4090-4108.

Lambin, E.R., Geist, HJ., và Lepers, E., (2003). Dynamics of land-use và land-cover change in tropical regions. Annual Review of Environment và Resources 28, 205-241.

Lam Dao Nguyen, Pham Bach Viet, Nguyen Thanh, M., Pham Thi Minh, Hoang Phi Phung, (2011). Change detection of lvà use và river bank in
Mekong Delta, Vietnam using time series remotely sensed data. J. Resour. Ecol. 2, 370374.

Niên giám thống kê tỉnh Cà Mau, (2017). Cục Thống kê tỉnh Cà Mau.

Pech, S., Sunada, K., (2008). Population growth và natural-resources pressures in the Mekong River Basin. AMBIO: A Journal of the Human Environment 37(3), 219-224.

Prabaharan, S., Srinivasa Raju, K., Lakshumanan, C., Ramalingam, M., (2010). Remote sensing và GIS applications on change detection study in coastal zone using multi temporal satellite data. Int. J. Geomat. Geosci. 1, 159-166.

Sheeja, R.V.,Joseph, S.,Jaya, D.S., Baiju, R.S., (2010). Land use and land cover changes over a century (1914-2007) in the Neyyar River Basin, Kerala: $\mathrm{A}$ remote sensing và GIS approach. Int.J. Digit. Earth 4, 258-270.

Sohail, A., (2012). Mapping Landcover/ Landuse và Coastline Change in the Eastern Mekong Delta (Viet Nam) from 1989 to 2002 using Remote Sensing. Master's Thesis, Royal Institute of Technology, Stockholm, Sweden.

Tian, Y., Yin, K., Lu, D., Hua, L., Zhao, Q., Wen, M, (2014). Examining land use và land cover spatiotemporal change and driving forces in Beijing from 1978 to 2010. Remote Sens. 6, 10593-10611.

Tran Hanh, Tran Thuc, Kervyn, M., (2015). Dynamics of Land Cover/ Land Use Changes in the Mekong Delta, 1973-2011: A Remote Sensing Analysis of the Tran Van Thoi District, Ca Mau Province, Vietnam. Remote Sensing 7, 2899-2925.

Vo Quoc Tuan, Oppelt, N., Leinenkugel, P., Kuenzer, C., (2013). Remote sensing in mapping mangrove ecosystems - An objectbased approach. Remote Sens. 5, 183-201. 